\title{
ON THE USE OF THE SHAPLEY VALUE IN POLITICAL CONFLICT RESOLUTION
}

\author{
G.N. Engelbrecht ${ }^{1}$, CSIR \\ and \\ A.P. Vos ${ }^{2}$, Fox Research Solutions
}

\begin{abstract}
This article delineates generic causes to internal conflict and proposes a coalition-forming methodology to allow for power sharing as one avenue of conflict resolution. A suitable framework to study causes to internal conflict should, at least, provide for big bad men versus people under pressure, recent versus historic events and an internal versus an external emphasis that may be employed to understand the rationale for internal conflict. As long as aggrieved parties are not allowed to address their grievances adequately, political conflict will emerge and, if not addressed timely, such conflict may lead to civil war. A conflict resolution mechanism based on the Shapley value is proposed to deal with internal conflict. The allocation of delegates, derived so that all parties have a say commensurate with their support bases, should allow for formal consensus to take place more readily than in cases where a particular party's representation in such a forum dominates the representation of the other parties. An algorithm to determine the number of votes or seats allocated to each of the parties to ensure equitable power sharing is also given.
\end{abstract}

The causal reasons for internal conflict and the proposed methodology to deal with such conflict was presented to prominent South African politicians and political scientists for comment. A favourable response regarding their acceptance of the methodology was elucidated.

\section{Introduction}

During the last fifty years, more than two hundred wars were fought. MishalliRam (2006), for example, analysed 133 ethnic-related conflicts over the period 1918

\footnotetext{
${ }^{1}$ Corresponding author: Built Environment, Council for Scientific and Industrial Research, P.O. Box 395, Pretoria, 0001 South Africa.

${ }^{2}$ Fox Research Solutions, P.O. Box 40576, Moreleta Ridge 0044, South Africa.
} 
to 2002 worldwide. Almost all of these were tantamount to civil war, that is, wars fought within a single country amongst its inhabitants. Civil wars take on a dynamic of their own which is distinct from interstate wars which are governed mainly by International Law. Civil wars are brutal affairs where anger, emotion and bitterness are exacerbated by the fact that family members, former colleagues and neighbours fight on opposite sides. Such wars cause physical destruction, set development back by decades or more and poison interrelationships in the community where they are being fought.

The resulting air of distrust that develops makes the achievement of peace even more difficult. To resolve civil war, the warring parties frequently seek the involvement of international interveners whom all the warring parties trust to some acceptable degree to act as facilitators in order to find solutions that may lead to peace. The main concern of the warring parties is that they will have a say in defining the peace they seek and realise their objectives for embarking on civil war to a degree that is acceptable to them.

The international interveners must therefore find a way to allow all the parties meaningful participation in the peace negotiations. This article will seek to explain that an important underlying cause for political conflict and civil war is the fact that groupings in a country are denied a say in matters affecting themselves and that by allowing coalition forming, aggrieved groups may choose the bargaining chamber to civil war. The Shapley value is used to develop a mechanism for effective coalition forming. Finally, it is important that political scientists and politicians subscribe to the concept for it to be gainfully employed. To that end, the views of prominent South African political scientists and political leaders on the proposed coalitionforming approach are reported.

\section{Causes of internal political conflict}

Internal conflict, and specifically its crystallisation in civil war, constitutes armed hostilities between groups within a country. The overarching motive for civil war is political by nature. From a realist perspective, albeit not at the international level, as proposed by Von Clausewitz ([1832] c1976), civil war could also be regarded as merely an extension of diplomacy at the national level.

\section{Contrasting perspectives}

Joseph Hanlon makes the case that most analysts accept that civil wars have multiple causes. However, there is no general agreement on specific roots and almost every claim to have identified a cause is disputed (Yanacopulos and Hanlon 2006:72). Hanlon also claims that arguments in the literature are acrimonious and 
arcane and tend to be ignored by policy-makers. Mack (2002) further states that policy-makers have neither the time nor the expertise to choose between competing explanations.

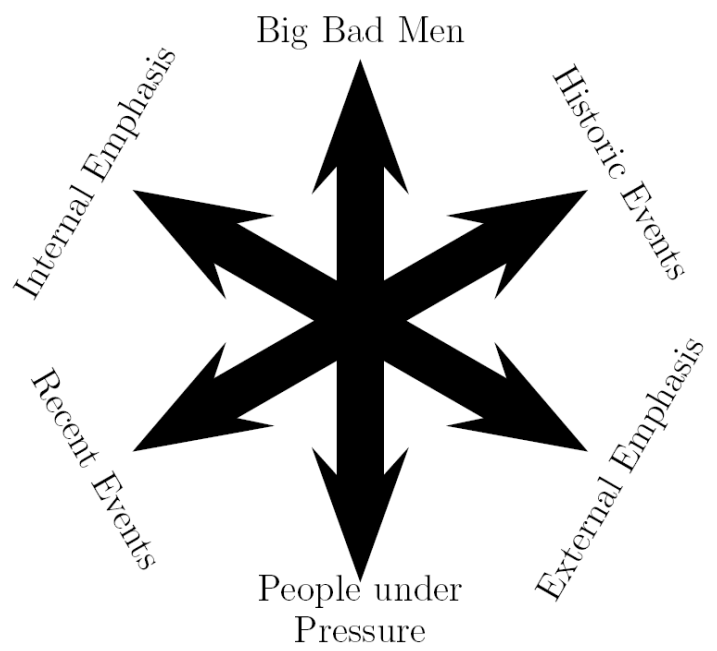

Figure 1: Contrasting perspectives about the causes of civil war

Yanacopulos and Hanlon (2006), however, provide a robust framework (depicted in Figure 1) to study the causes of civil war or internal conflict. To analyse the causes of internal conflict they propose a set of three contrasting perspectives which could be used, viz.

- $\quad$ people under pressure versus big bad men;

- $\quad$ internal versus external emphasis; and

- historic versus recent events.

The above three perspectives cannot be studied in isolation as they are mutually inclusive concepts.

Because of its relative simplicity and the notion that it provides a workable explanation for most of the time, this framework was chosen to explain the causes of civil war and other internal political conflicts. However, it is acknowledged that a notable weakness of this model is that it does not explain the rationale for coups to 
gain control of the state. Thus, the "small bad men" are evaluated as a force for political conflict only after they have become "big bad men".

\section{People under pressure versus big bad men}

"Big bad men" are governments, leaders, presidents, dictators or institutional heads who act contrary to the interests of the people who become involved in internal conflict. Typically, they have sufficient power to make decisions and implement them without referring to the citizens they govern or affect. For example, a dictator with a secure power base may act without taking the interests of the country's inhabitants into account. In turn, such unilateral actions pressurise the people which, in turn, results in adverse effects. This leads to grievances, economic hardship or environmental issues that cannot be readily resolved.

People will react in different ways in order to address their grievances. They may seek coalitions with others in order to form majorities that have the power to address their problems. Failing that, they may become so frustrated that they turn to some form of aggression to vent their feelings or to address their grievances (Gurr 175:75). This signifies the beginning of political conflict and civil war. The Nigerian Civil War, also known as the Biafran War, serves as an example. The war lasted from 6 July 1967 to 13 January 1970. It was a political conflict caused by the attempted secession of the south-eastern provinces of Nigeria as the self-proclaimed Republic of Biafra. An estimated 1,2 million casualties resulted with some animosities continuing to linger on to this day (Draper 1999).

At Nigeria's independence, a conservative political alliance was formed between the leading Hausa and Igbo political parties that were constituted along ethnic lines, which ruled Nigeria from 1960 to 1966. This alliance excluded the western Yoruba people. The well-educated Igbo people were considered by many to be the main beneficiaries of this alliance, taking most of the top jobs and leading business opportunities in the Nigerian federation. After the successful coup on 16 January 1966 by Igbo Army officers, the status quo was largely maintained at the cost of the south-eastern provinces. Their exclusion from power made many fear that revenues from the newly discovered oil fields would be used to benefit areas in the north and west rather than their own. Pressure mounted and the Nigerian civil war became inevitable.

It should be noted that the above brief explanation disregards the debate on fight, freeze and flee as underpinned by the theories of psychology (Vertzberger 1990) and rather concentrates on the "fight" element which may be regarded as extremist politics. It is submitted that, as long as people under pressure do not adopt a fighting 
posture against big bad men, the inherent political conflict might never escalate to civil war.

\section{Internal versus external emphasis}

In some cases actions or decisions external to a particular country may lead to political conflict within that country, whereas in other cases political conflict is caused by decisions or actions taken within the country in question.

An example of external emphasis is the Mozambican Civil War that began in Mozambique following that country's independence in 1975. The ruling party, Frelimo, was violently opposed from 1977 by the Rhodesian and later South African-funded opposition group known as Renamo. Over five million civilians were displaced, 900000 are thought to have died in fighting and from starvation and many were made amputees by land mines, a legacy from the war that continues to plague Mozambique (Arnold 2005:711).

An example of internal emphasis would be the struggle against apartheid in South Africa. The South African government elected in 1948 decided on a course of action of domination by one racial group over any other racial group or groups in order to safeguard their constituents' political power (Scott et al. 1975). Thus the seeds for this potential civil war had an internal emphasis.

\section{Historic versus recent events}

Causes for civil war sometimes originate in historic events whilst at other times they are initiated by recent or even current events.

The Anglo-Norman mercenaries who went to Ireland under Richard de Clare, Second Earl of Pembroke, nicknamed Strongbow, in 1169 marked the beginning of more than 800 years of direct English involvement in Ireland. The English crown did not begin asserting full control of the island until after the English Reformation, when questions over the loyalty of Irish vassals provided the initial impetus for a series of military campaigns between 1534 and 1691. This period was also marked by an official English policy of plantation which led to the arrival of thousands of English and Scottish Protestant settlers in Ireland.

From this period on, sectarian conflict became a recurrent theme in Irish history (Annaidh 1999). To understand the causal relationships of the problems in Ireland, a study of historic events over the last eight centuries that may have influenced Irish history is necessary. Depending on a chosen time line, the troubles in Ireland in, for example, 1540 could be viewed as the result of recent events, whilst the troubles in Ireland today could be viewed as the result of historic events. 


\section{A juxtaposition of contrasting perspectives}

Yanacopulos and Hanlon (2006) argue that the three contrasting perspectives (cited earlier in the text) are in essence caricatures and simplifications of real situations. However, by juxtaposing all three perspectives, insight into the causes of civil war might be found.

Consider the genocide in Rwanda. The Rwandan Genocide was the mass extermination of hundreds of thousands of ethnic Tutsis and moderate Hutu sympathisers in the period 6 April to mid-July 1994. It was the largest atrocity during the Rwandan civil war. The genocide was by and large carried out by two extremist Hutu militia groups, the Interahamwe and the Impuzamugambi. At least 500000 Tutsis and thousands of moderate Hutus died in the genocide (Human Rights Watch, 1999). In a historical context, Rwanda's colonial masters, being Germany and Belgium in succession, favoured the Tutsi minority group and promoted their interests at the expense of the majority Hutus. In turn, this lead to mounting pressure in the Hutu population to rectify their perceived inferior position.

Thus, big bad men, external to the country and some time ago, inadvertently caused a series of events to lead Rwanda to civil war and genocide. At the root of the genocide was the initial Hutu perception that they were unable to influence dayto-day events that impacted adversely on them.

\section{Major contributing causes to internal political conflict}

A careful analysis of numerous civil wars within the framework of the three contrasting perspectives leads to the following observations:

- $\quad$ Big bad men, however well intentioned, at some time in the history of the country concerned cause grievances in particular segments of the population.

- As long as they are hopeful of resolving their grievances, groups will attempt all avenues to better the situation.

- When groups, whether in the minority or not, cannot resolve their grievances, they may choose violence such as coups, civil war or revolution as a mechanism to address such grievances.

Yanacopulos and Hanlon (2006) comment that richer countries with more established democracies have fewer civil wars. Studies suggest that even for relatively poor countries, strong democracy provides protection against civil war. They ascribe this observation to individual and group rights being respected and the relationship between the state and its citizens being strong enough to allow 
grievances to be dealt with adequately. In other words, established democracies tend to allow avenues for minorities to address their grievances.

In conclusion, as long as aggrieved parties are not allowed to address their grievances adequately, political conflict will emerge and, if not addressed timely, such conflict may lead to civil war. Not only should governments and other leaders heed this fact in averting political conflict, but during the seeking of peace by all concerned, international interveners should also keep this in mind.

\section{Coalition forming as a conflict-resolution mechanism}

Suppose that in some country a conflict or dispute arises between $\mathrm{n}$ parties and that the $i$ th party has support from a proportion, $p_{i}$, of the population. If a proportional voting system is being used to resolve their differences or grievances and the $j$ th party's support is $p_{j}>0.5$, then that party's policy will prevail.

Should a system of consensus be adopted and one or more parties not agree to a particular resolution, a stalemate will occur. Should no party have outright majority support from the population, all the parties may seek coalitions with other parties to further their own agendas or policies. As a result, minorities might be able to influence decision outcomes to some degree and this, in turn, may lead to more lasting buy-in into resolutions made by the group. If the idea of coalition forming could be extended to allow it under all circumstances and to the degree that is commensurate with the political support of all parties, it may enhance lasting conflict-resolution decisions. Game theory may provide for such a course of action.

\section{Game theory}

Game theory has its origins in the ability of man to model his environment. However, game theory is a relatively new scientific development. The first comprehensive work in this regard was the book Theory of Games and Economic Behaviour by John von Neumann and O. Morgenster. This landmark book was first published in 1928 by the Princeton University Press. The book sparked off a flurry of academic activity and game theory soon became a popular modelling method.

Straffin (1993) defines game theory as the logical analysis of situations of conflict and co-operation. The simplest type of game is a one-person game, also called a game against nature. A one-person game is a game in which a single player makes a decision in the face of an environment assumed to be indifferent or neutral. A two-person game is a game where two players make decisions and where the outcome of their decisions is interactively influenced by both sets of decisions. Twoperson games are the most elementary interactive situations of general concern to 
the student of game theory. Games that involve more than two players are called $n$ person games.

In a finite game, each player has a finite number of strategies and a game could be presented by the matrix $A$, with each of its entries consisting of a list containing the $n$ players' payoffs. Consider a two-person game: The two players are referred to as the "row player" and the "column player" respectively and there will be two payoffs in every entry of the matrix. For example, in the entry $a_{i j}$, the first payoff in the entry is associated with the row player for playing his or her $i$ th strategy, and the second payoff in the entry is associated with the column player for playing his or her $j$ th strategy. In game theory, payoffs are normally determined by the utility of the actual payoff to the player in question.

The matrix

$$
A=\left[\begin{array}{ll}
(1,2) & (2,1) \\
(2,1) & (3,3)
\end{array}\right]
$$

serves as an example of a two-person game where both players have two strategies to choose from. Also, by inspection, it is noted that both players should consistently choose their second strategies to optimise their payoffs. Various methods to determine optimal strategies for all players exist. For the reader not familiar with game theory, a very good introduction is the book by Owen (1995). His notation is followed in the remainder of this article.

To date, it appears that no theorem has been given for $n$-person games. This has led many mathematicians to look for other solution concepts. One mathematician, Shapley (1953), published another solution concept for $n$-person games that became known as the Shapley value.

\section{Shapley value}

The Shapley value is a power index that is used to determine the extent of power that all players in an $n$-person game have when coalition forming takes place. A coalition for $n$-person games is defined as follows: If

$$
N=\{1,2, \ldots, n\}
$$

is the set of all players, then any non-empty subset of $N$, including $N$ itself and all the one-element subsets, is called a coalition (Owen 1995:213). Furthermore, when a coalition forms in an $n$-person game under conditions of individual and 
collective rationality, the $n$-tuple of payments to the players is called an imputation. The $n$-tuple of payments to the players is also known as the Shapley value of the game. A carrier for a game $v$ is a coalition $T$ such that for any set of players, $S$, the Shapley value would be

$$
v(S)=v(S \cap T) .
$$

A dummy player is any player who does not belong to a carrier, that is, such a player contributes nothing to a coalition. It follows that a dummy player, if left out of a coalition, will not influence the success or failure of that coalition. Let $v$ be an $n$-person game and let $\pi$ be any permutation of the set $N$, then, by $\pi v$ is meant the game $u$ such that for any $S=\left\{i_{1}, \ldots, i_{s}\right\}$ it holds that

$$
u\left(\left\{\pi\left(i_{1}\right), \ldots, \pi\left(i_{s}\right)\right\}\right)=v(S)
$$

where the utility function $u$ comprises the utilities associated with the $s$ permutations $\pi\left(i_{i}\right)$ regarding the $i$ th carrier, and the game $\pi v$ is effectively nothing other than the game $v$ with the roles of the players interchanged by the permutation $\pi$. Therefore, by the value of the game $v$ is meant the imputation $\varphi[v]$ that must satisfy the following three axioms:

Axiom 1: If $\mathrm{S}$ is any carrier of $\mathrm{v}$, then

$$
\sum_{S} \varphi[v]=v(S)
$$

Axiom 2: For any permutation $\pi$ and $i \in N$, it is true that

$$
\varphi_{\pi(i)}[\pi v]=\varphi_{i}[v]
$$

Axiom 3: If $u$ is any game, then

$$
\varphi_{i}[u+v]=\varphi_{i}[u]+\varphi_{i}[v] .
$$

The Shapley value is calculated by (Morris 1994:180) 


$$
\varphi_{i}[v]=\sum_{T \subset N, i \in T} \frac{(t-1) !(n-t) !}{n !}[v(T)-v[T-\{i\}]]
$$

where

- $\quad t$ is the number of entities in a winning coalition that the $i$ th player is part of, and

- $\quad$ the $i$ th player is not a dummy player, and

- $v(T)-v(T-\{i\})=0$ if no player contributes anything, and

- $v(T)-v(T-\{i\})=1$ if the sum of the contributions is larger than $v(T)$.

Consider a country with four political parties, 1, 2, 3 and 4 that have 10\%, 20\%, $30 \%$ and $40 \%$ of the vote respectively. Decisions are made by simple majority vote. This situation represents a four-person game in which the winning coalitions are

$$
\{2,4\},\{3,4\},\{1,2,3\},\{1,3,4\},\{2,3,4\} \text { and }\{1,2,3,4\} \text {. }
$$

From the discussion, note that $\varphi[v]=\left[\varphi_{1}, \varphi_{2}, \varphi_{3}, \varphi_{4}\right]$. In order to find the power index value associated with political party $1, \varphi_{1}$, it is determined that the only winning coalition $T$ such that $T-\left\{i_{1}\right\}$ is not a winning coalition, is the coalition $\{1,2,3\}$. Thus $t=3$ and from equation 1 


$$
\begin{aligned}
\varphi_{1} & =\frac{(t-1) !(n-t) !}{n !}[1] \\
& =\frac{(3-1) !(4-3) !}{4 !}[1] \\
& =\frac{2 ! 1 !}{4 !} \\
& =\frac{1}{12} .
\end{aligned}
$$

Note that for all other coalitions, $[v(T)-v(T-\{i\})]$ in equation 1 evaluates to zero and hence equation 2 is sufficient.

In order to find $\varphi_{2}$, it is noted that the coalitions $\{2,4\},\{1,2,3\}$ and $\{2,3,4\}$ numbered $J=1,2,3$ respectively are the only winning coalitions which will not win if player 2 is removed from them and then

$$
\begin{aligned}
\varphi_{2} & =\sum_{j=1}^{3} \frac{\left(t_{j}-1\right) !\left(n-t_{j}\right) !}{n !}[1] \\
& =\frac{1}{12}+\frac{1}{12}+\frac{1}{12} \\
& =\frac{1}{4}
\end{aligned}
$$

The values $\varphi_{3}$ and $\varphi_{4}$ are found similarly and the Shapley value for this game is the imputation $\varphi=\left(\frac{1}{12}, \frac{1}{4}, \frac{1}{4}, \frac{5}{12}\right)$.

\section{The inverse of the Shapley value}

By the inverse of the Shapley value is meant the input values that would result in coalitions such that equation 1 would deliver a previously determined Shapley value. 
From the discussion at the beginning of this section, by finding the inverse to the Shapley value seats or voting stock in a decision-making body could be assigned such that $\varphi$ reflects the power base of the various parties. For the example above on a country with four parties, voting stock should be assigned to ensure $\varphi=\{0.1,0.2,0.3,0.4\}$.

Dragan (2005) proposed a dynamic algorithm for finding semi- or weighted values for transferable utility games. This allows, inter alia, for the finding of the inverse function of the Shapley value. However, numerical methods may prove to be more readily implementable and will yield acceptable accuracy. A numerical method to find the inverse of the Shapley value will be described directly and the validity of the previous statement will then be revisited.

\section{Shapley value behaviour}

It is noteworthy to mention that the Shapley value behaves in a non-continuous manner. This is due to the fact that the elements of $\varphi$ are multiples of $\frac{1}{n !}$. Moreover, in the trivial case where only one player participates in the game, $\varphi=1$. When two players participate in a game, $\varphi=\{1,0\}$ when the first player has more voting stock than the second player, $\varphi=\{0,1\}$ when the second player has more voting stock than the first player and $\varphi=\left\{\frac{1}{2}, \frac{1}{2}\right\}$ when the two players have exactly the same voting stock.

In the latter case, it is noted that not only are the elements of $\varphi$ multiples of $\frac{1}{2 !}$ but changes in $\varphi$ are also of that order. Consider equation 2. Should voting stock of approximately $10.01 \%, 19.89 \%, 30.03 \%$ and $40.05 \%$ be allocated to the four players and it is varied from that position to voting stock of approximately $10.02 \%, 19.92 \%, 30.07 \%$ and $39.97 \%$ respectively, the Shapley value will remain constant at

$$
\begin{aligned}
\boldsymbol{\varphi} & =\left\{\frac{4}{4 !}, \frac{4}{4 !}, \frac{4}{4 !}, \frac{12}{4 !}\right\} \\
& =\left\{\frac{1}{6}, \frac{1}{6}, \frac{1}{6}, \frac{1}{2}\right\} .
\end{aligned}
$$


In the above discussion, it was shown that the Shapley value elements -

- may assume specific values only at particular voting stock situations such as a $50 \%$ stock for both players in the two-player scenario, and

- may assume specific values over a range of voting stock scenarios such as depicted in equation 3 ,

- $\quad$ whilst changing these values at multiples of $\frac{1}{n !}$ at the changing points, and

- finally, it is implicit in the Shapley value that for $n$ small the changes in the elements of $\varphi$ relating to changes in voting stock are more pronounced than for $n$ large.

\section{Search algorithm}

The authors propose a numerical search algorithm for finding the required voting stock or inverse Shapley value for a given Shapely value as shown in Figure 2 where

- $n$ denotes the number of players in the game,

- $\sigma$ denotes the search step length,

- $\varphi$ denotes the required Shapley value,

- $\quad \rho$ denotes the imputation that must hold the algorithm's start position and the found inverse Shapley value,

- $\varphi^{*}$ denotes the computed Shapley value by using $\rho$ as the input or voting stock,

- $\quad F$ denotes a figure of merit for the current iteration and is computed by

$$
F=\sum_{i=1}^{n}\left(\varphi_{i}^{*}-\varphi_{i}\right)^{2}
$$

whilst $F^{*}$ denotes the figure of merit for the previous iteration, and

- the Dummy variable is a Boolean value that evaluates YES if there are dummy players present in $\varphi^{*}$ and NO if there are no dummy players present in $\varphi^{*}$. 


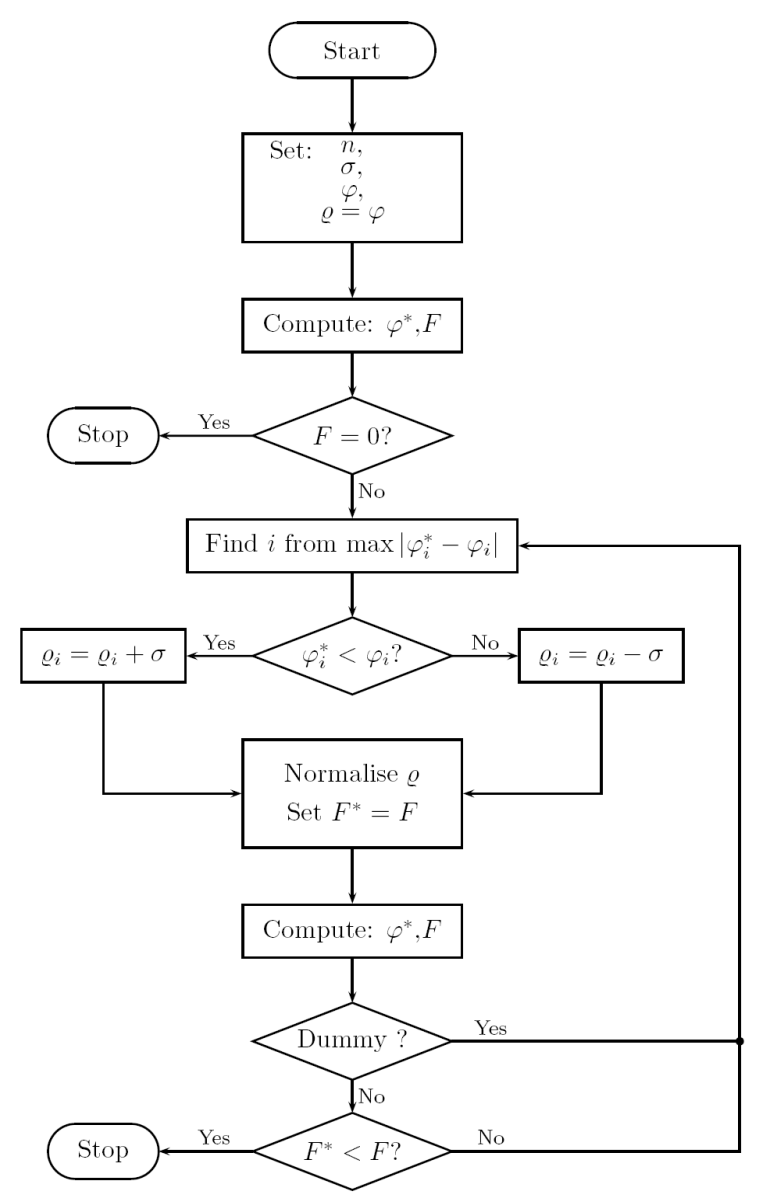

Figure 2: Algorithm for finding inverse Shapley values

The algorithm finds the inverse Shapley value by searching from a given start position held by $\rho$ and seeking a better solution by finding the element in $\rho$ that is furthest away from its corresponding element in $\varphi^{*}$ and then moves that element of $\rho$ by a fixed step length $\sigma$ in the required direction. On completion, $\rho$ is normalised by setting all normalised elements to 


$$
\rho_{j}^{N}=\frac{\rho_{j}}{\sum_{i=1}^{n} \rho_{i}}
$$

The first stop rule, $F=0$ is necessary to identify situations were

$$
\varphi_{i}^{*}=\rho_{i} \quad \forall i
$$

This always occurs when $\varphi=\rho$ with $\rho_{1}=\rho_{2}=\ldots=\rho_{n}$ and as a result, $\varphi^{*}=\varphi$. Moreover, it could readily be shown that it might also occur in some instances when $\rho_{1} \neq \rho_{2} \neq \ldots \neq \rho_{n}$.

The second stop rule is more complex as it requires that no dummy players are present in the solution and that the figure of merit from the previous iteration, $F^{*}$, is smaller than the figure of merit for the current iteration, $F$. Should a dummy player be present in the solution, the algorithm will disregard the status of $F^{*}$ and $F$, and will carry out further iterations until no dummy players are present. Only then will the algorithm take the status of $F^{*}$ and $F$ into account.

Note that the found inverse Shapley value, $\rho$, is reported when the stop rule terminates the algorithm and only the value of $\rho$ at the last iteration is reported. However, if $\rho$ is reported at every iteration, the set of values that $\varphi^{*}$ may contain whilst $\varphi^{*}$ remains constant may be found with accuracy $\delta \leq \sigma$. It follows that for required accuracy, $\delta, \sigma$ must be chosen such that $\sigma \leq \delta$. Note that if the setting $\sigma=\delta$ is applied, the normalisation of $\rho$ will have the effect of reducing $\sigma$ and it follows that the reduced value $\sigma^{\prime}<\delta$. 
Applying the algorithm

Consider the 2004 general elections in South Africa. The results for the eight parties with most significant voter support are given in Table 1 (Greben 2007).

Table 1: Election results: South Africa 2004

\begin{tabular}{lcccccccc}
\hline \hline Party & ANC & DA & IFP & UDM & ID & NNP & ACDP & VFP \\
\hline Poll $(\%)$ & 69.7 & 12.4 & 7.0 & 2.3 & 1.7 & 1.7 & 1.6 & 0.9 \\
\hline \hline
\end{tabular}

Supposing that the eight parties reflected in Table 1 are the only parties in parliament, seats in the house will be allocated according to the ratio

$$
\rho=\{0.76,0.127,0.071,0.023,0.017,0.017,0.016,0.009\}
$$

whereas the Shapley value associated with equation 4 is

$$
\varphi^{*}=\{1,0,0,0,0,0,0,0\}
$$

with $F=0.103404$.

From equation 5 it is clear that all power resides with the African National Congress (ANC). Now, suppose the ANC wishes to form a government of national unity with all eight parties, and to achieve this, they are willing to sacrifice some of their power provided that the power sharing model allows for power by coalition forming to the extent that it reflects as closely as possible the election results.

By using the given algorithm for finding inverse Shapley values, it is found that by setting

$\rho=\{0.4691,0.2384,0.1346,0.0442,0.0326,0.0326,0.0307,0.0173\}$

the power distribution in the proposed government of national unity would be

$\varphi^{*}=\{0.6785,0.0595,0.0595,0.0595,0.0595,0.0595,0.0119,0.0119\}$ 
with $F=0.011045$.

It is of interest that, in this particular case, $F=0.010417$ is the minimum for

$\rho=\{0.4698,0.2381,0.1344,0.0441,0.0326,0.0326,0.0307,0.0172\}$

and its associated imputation

$\varphi^{*}=\{0.7142,0.0476,0.0476,0.0476,0.0476,0.0476,0.0476,0\}$

Although $\mathrm{F}$ is minimum, that is, the imputation $\varphi^{*}$ is closest to the required imputation $\varphi$, because of the fact that $\varphi^{*}$ includes a dummy player, the requirement for an all-inclusive situation is not met and by further iterations of the algorithm, a position where no dummy players are present and with $F$ as small as possible is found.

At this point, the ANC's power allocation reflects closely their results in the general election, whereas the Democratic Alliance (DA), Inkatha Freedom Party (IFP), United Democratic Movement (UDM), Independent Democrats (ID) and New National Party (NNP) may form winning coalitions for approximately $6 \%$ of the time and the African Christian Democratic Party (ACDP) and Freedom Front Plus $(\mathrm{VF}+)$ may form winning coalitions for approximately $1 \%$ of the time. Although the latter amounts may seem small, it is a far better situation for these parties to be in than that of being a dummy player only.

On the other hand, for the ANC this could become problematic as the seven other parties may consistently form a coalition with about $53 \%$ of the seats in parliament. In a mature democracy, the probability of the opposition acting in such a manner should be very low, but should it occur, this would be the price to the ruling party for realising a dream of a rainbow nation with a government of national unity as advocated by some.

\section{Proposed model for conflict resolution}

One view of consensus decision-making defines the process as a decisionmaking process that not only seeks the agreement of most participants, but also to resolve or mitigate the objections of the minority to achieve the most agreeable 
decision. Consensus is usually defined as meaning both general agreement, and the process of getting to such agreement. Consensus decision-making is thus concerned primarily with that process (Bounds et al. 1995:538).

Consider the situation where a country is in the midst of a civil war. After some time has elapsed, the various warring parties are tired of the war and are willing to commence talks about talks. During these preliminary talks, and bearing in mind the observation that, if the grievances of parties are not addressed adequately and timely, political conflict and eventually civil war could emerge, which could be considered as the root of the conflict, a consensus must be found to ensure the meaningful participation of all parties in the final solution to the conflict.

The problem is that the proportion of delegates may not reflect the true support base of the various warring parties. Therefore, it is necessary for the warring parties to agree on the size of their respective support bases. But one of the parties may, because of its perceived or previously agreed support, warrant more than $50 \%$ of the delegates and in this case, the other parties become dummy players with no power.

The idea is that the number of delegates for every party must be chosen so that the parties must work together to derive an equitable solution, that is, the parties must be able to form meaningful coalitions for a proportion of the decision events that reflects their respective support bases. This may result in the various factions being more responsive to the idea of talking about talks and set the scene for derived solutions at the peace talks to be acceptable to all of the warring parties. The allocation of delegates so derived should allow for formal consensus to take place more readily than in cases where a particular party's representation in such a forum dominates the representation of the other parties.

The scenario that was sketched assumes that a stalemate has occurred, the civil war was based on extremist politics and not on radical militarism, and the status quo is no longer acceptable to the involved parties. In turn, this leads to the assumption that all parties in the negotiation will be willing to relinquish some of their original goals and that none of them will exercise absolute rule. Such a situation, if not accepted by the warring parties, results in a conflict without a victor and a loser. This, in itself, may be the basis for a later conflict. One or more parties may be able to regroup, re-supply its forces and commence hostilities. On the other hand, a clear victor and a clear loser also will not guarantee a lasting peace. For example, it is often argued that the seeds of the Second World War were inherent to the Treaty of Versailles that marked the end of the First World War (International Crisis Behavior Project 2009). 


\section{Political views on the proposed model}

For the proposed model to be accepted by governments and international interveners as a useful tool in political conflict resolution, the causes for internal political conflict (described earlier in the discussion) and the proposed coalitionforming mechanism should be regarded by them to be at least adequate.

To that end, various prominent South African politicians and political scientists were asked to express their views regarding the ideas proposed in this article. At least one senior politician in each of the South African political parties represented in parliament and at least one senior political scientist at South African universities and other research institutions were approached. Five politicians and seven scientists responded. In terms of the South African Market Research Association Code of Conduct that regulates market research in South Africa, their names and affiliations will not be reported on.

The views obtained from the politicians and political scientists are reported under the following headings:

- $\quad$ Causes for political conflict, and

- Coalition forming as a conflict-resolution mechanism.

\section{Causes for internal political conflict}

The respondents were asked to rate the validity of the seven causes of internal political conflict as proposed by Yanacopulos and Hanlon (2006). The survey results indicated that there is a general consensus that the framework is a requisite exposition of the causes underlying internal political conflict. Given these causes, the respondents were then asked to rank them in order of importance. The results are reported in Table 2. Note that the respondents did not complete the rankings fully in all cases.

Table 2: Root causes of political conflict

\begin{tabular}{|l|c|c|c|c|c|c|c|}
\hline Rankings & $1^{\text {st }}$ & $2^{\text {nd }}$ & $3^{\text {rd }}$ & $4^{\text {th }}$ & $t^{\text {th }}$ & $6^{\text {th }}$ & $7^{\text {th }}$ \\
\hline People under pressure & & 2 & 1 & 1 & 1 & 3 & 1 \\
\hline Big Bad Men & 1 & 2 & 3 & & 3 & 1 & \\
\hline Internal Emphasis & 1 & 2 & 2 & 2 & 3 & & \\
\hline External Emphasis & & & & 2 & & 4 & 3 \\
\hline Historic Events & 1 & 2 & 1 & 3 & 1 & & 1 \\
\hline Recent Events & 1 & 3 & 1 & 2 & 1 & 1 & 2 \\
\hline A Juxtaposition & 6 & & 1 & 1 & & & 1 \\
\hline
\end{tabular}


The survey revealed that a juxtaposition of the above-mentioned causes was adjudged the most important cause of conflict amongst all respondents. However, amongst political scientists, big bad men, internal emphasis and recent events were also most prominent. The causes - people under pressure, big bad men, internal emphasis, historic and recent events - were all of importance. In general, the external emphasis was adjudged to be of least significance by both politicians and political scientists in near equal ratios. These results, coupled to some open-ended comments, demonstrated the willingness to accept the ideas about the causes for political conflict, described previously, by the participants.

\section{Coalition forming as a conflict-resolution mechanism}

Regarding conflict-resolution mechanisms, the respondents were asked to rate given mechanisms on a five-point Likert-type scale that was mapped in the interval $[0,100]$. The overall results are shown in Figure 3.

The results support the view held by Yanacopulos and Hanlon (2006) that countries with more established democracies have fewer civil wars. However, as few countries in the world have established democracies, this mechanism may have a reduced impact on political conflict resolution. Coalition forming as previously described is viewed by the respondents to be a strong contender as a conflictresolution mechanism. It can also be argued that by using a coalition-forming mechanism, people will have a more substantial say in their future and in turn, this may lead to hope being generated amongst them regarding solving their grievances in a relatively peaceful manner.

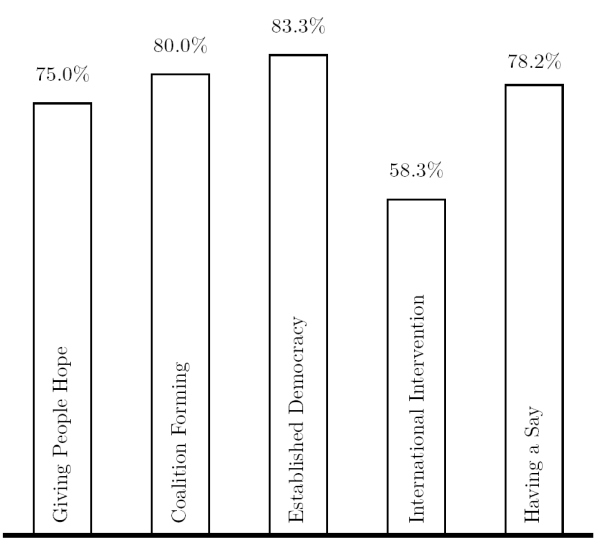

Figure 3: Most effective conflict resolution mechanisms 


\section{Conclusion}

The causes underlying political conflict and its manifestation in civil war mainly comprises a juxtaposition of three contrasting perspectives, viz. people under pressure versus big bad men; an internal versus an external emphasis, and historic versus recent events. Although established democracies have fewer civil wars, such democracies might fail or in the absence of established democracy, political conflict may cause civil war. In resolving civil war, a coalition-forming mechanism may prove valuable.

The warring parties will have a say in the peace they seek and, in turn, hope for the future will be fostered. The use of the inverse Shapley value as proposed in this article is one way of implementing a coalition-forming mechanism where the warring parties will have a say in the peace they seek to an extent that is commensurate with their respective power bases.

\section{References}

Annaidh, S.M. 1999. Irish History. Bath: Paragon.

Arnold, G. 2005. Africa: A Modern History. London: Atlantic Books.

Bounds, G.M., Dobbins, G.H. and Fowler, O.S. 1995. Management - A Total Quality Perspective. Cincinnati, Ohio: South-Western College Publishing.

Dragan, I. 2005. On the Inverse Problem for Semivalues of Cooperative TU Games. Proceedings of the 6th World Congress of Structural and Multidisciplinary Optimization, Rio de Janeiro, Brazil.

Draper, I.M. 1999. Shadows: Airlift and Airwar in Biafra and Nigeria 1967-1970. Aldershot, Hants [England]: Hikoki Publications.

Greben, J.M. 2007. A Theory of Quantitative Trend Analysis and its Applicability to South African General Elections. South African Journal of Sciences, 103:232238.

Gurr, T. Psychological Factors in Civil Violence, in Sarkesion, S. (ed). 1975. Revolutionary Guerrilla Warfare, Chicago: Precedent Publishers Inc.

Huggins, C. and Clover, J. (eds). 2005. From the Ground Up - Land Rights, Conflict and Peace in Sub-Saharan Africa. Pretoria: Institute for Security Studies.

International Crisis Behavior Project, 2009. ICB Data Viewer Version 9 [Online]. Available: http://www.cidcm.umd.edu/icb/dataviewer/ [2009, 28 April]. 
Human Rights Watch, 1999. Leave None to Tell the Story: Genocide in Rwanda [Online]. Available: http://www.hrw.org/legacy/reports/1999/rwanda/Geno1-301.htm\#P6_41 [2009, 28 April].

Mack, A. 2002. Civil War: Academic Research and the Policy Community. Journal of Peace Research, 39:515-525.

Mishalli-Ram, M. 2006. Ethnic Diversity, Issues, and International Crisis Dynamics, 1918-2002. Journal of Peace Research, 43(5):583-600.

Morris, P. 1994. Introduction to Game Theory. New York: Springer.

Owen, G. 1995. Game Theory. 3rd ed. San Diego: Academic Press.

Scott, G., Huggins, M. and Huggins, N. Guerrilla Warfare: Predisposing and Precipitation Factors, in Sarkesian, S. (ed). 1975. Revolutionary Guerrilla Warfare, Chicago: Precedent Publishers Inc.

Shapley, L. 1953. A Value for $n$-person Games. Contributions to the Theory of Games. Ann. Math. Studies, Princeton University Press, 28:307-317.

Straffin, P. D. 1993. Game Theory and Strategy. New York: The Mathematical Association of America.

Vertzberger, Y. 1990. The World in their Minds: Information Processing, Cognition and Perception in Foreign Policy Decision-making. Stanford, CA: Stanford University Press.

Von Clausewitz, C. [1832] c1976. On War. Princeton, NJ: Princeton University Press.

Yanacopulos, H. and Hanlon, J. (eds). 2006. Civil War, Civil Peace. Oxford, UK: James Curry. 